\title{
Simultaneous determination of atorvastatin and ezetimibe from combined pharmaceutical products by micellar electrokinetic capillary chromatography
}

\author{
Blanka Székely-Szentmiklósi1 ${ }^{*}$, Gabriel Hancu${ }^{1}$, István Székely-Szentmiklósi², Béla Kovács², \\ Hajnal Kelemen ${ }^{1}$
}

\begin{abstract}
${ }^{1}$ Department of Pharmaceutical Chemistry, Faculty of Pharmacy, University of Medicine and Pharmacy, Tirgu Mureş, Romania, ${ }^{2}$ Technological Development Department, Gedeon Richter Romania, Tîrgu Mureş, Romania
\end{abstract}

\begin{abstract}
A rapid and sensitive micellar electrokinetic capillary chromatography method with UV photodiodearray detection was developed for the simultaneous determination of atorvastatin and ezetimibe in fixed dose drug combination. Experimental conditions such as buffer concentration and $\mathrm{pH}$, surfactant concentration, system temperature, applied voltage, injection parameters were optimized in order to improve the efficiency of the separation. The best results were obtained when using fused silica capillary (48 cm length X $50 \mu \mathrm{m}$ ID) and $25 \mathrm{mM}$ borate buffer electrolyte at $\mathrm{pH} 9.3$ containing $25 \mathrm{mM} \mathrm{SDS},+30$ $\mathrm{kV}$ applied voltage, $20^{\circ} \mathrm{C}$ system temperature. The separation was achieved in approximately 2 minutes, with a resolution of 7.02 , the order of migration being atorvastatin followed by ezetimibe. The analytical performance of the method was verified with regard to linearity, precision, robustness and the limit of detection and quantification were calculated.
\end{abstract}

Uniterms: Micellar Electrokinetic Capillary Chromatography. Fixed Dose Drug Combination. Atorvastatin. Ezetimibe.

\section{INTRODUCTION}

Ezetimibe (EZE) and atorvastatin (ATO) are two lipid-lowering compounds with complementary mechanisms of action (Ballantyne et al., 2003). ATO, (3R,5R)-7-[2-(4-fluorophenyl)-3-phenyl-4(phenylcarbamoyl)-5-(propan-2-yl)-1H-pyrrol-1-yl]3,5-dihydroxyheptanoic acid, lowers plasma cholesterol and lipoprotein levels by inhibiting 3-hydroxy-3methylglutaryl-coenzyme A (HMG-CoA) reductase and cholesterol synthesis by increasing the number of hepatic low-density lipoprotein (LDL) receptors on the cell-surface to enhance uptake and catabolism of LDL (Malhotra, Goa, 2001). EZE, (3R,4S)-1-(4-fluorophenyl)3-[(3S)-3-(4-fluorophenyl)-3-hydroxypropyl]-4-(4hydroxyphenyl)azetidin-2-one, acts by decreasing cholesterol absorption in the small intestine, leading to

*Coresspondence: B. Székely-Szentmiklósi. Department of Pharmaceutical Chemistry. Faculty of Pharmacy. University of Medicine and Pharmacy of Tîrgu Mureş. Gh. Marinescu 38, 540139 Tîrgu Mureş, Romania. E-mail: simoblanki@yahoo.com, blanka.szekely@umftgm.ro a decrease in the delivery of intestinal cholesterol to the liver. This causes a reduction of hepatic cholesterol stores and an increase in clearance of cholesterol from blood (Ara et al., 2008). The chemical structures of the two analytes ATO and EZE are presented in Figure 1.

Combining the different mechanisms of action of these agents appears to provide substantial reductions in LDL cholesterol, with additional favorable changes in total cholesterol. Clinical studies have shown that coadministration of ATO and EZE was significantly more effective at reducing LDL cholesterol concentrations than ATO and EZE alone. EZE co-administered with an HMGCoA reductase inhibitor is indicated as adjunctive therapy to diet for use in patients with primary hypercholesterolaemia who are not appropriately controlled with a statin alone (Gagné, Gaudet, Bruckert, 2002).

Taking into consideration the great prevalence and importance of fixed dose combination in modern therapy, the elaboration of new methods of analysis for the simultaneous determination of combined substances represents a necessity and also a challenge for analyst. 


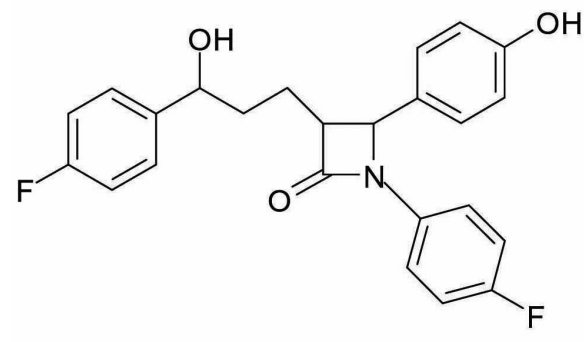

Ezetimibe - EZE

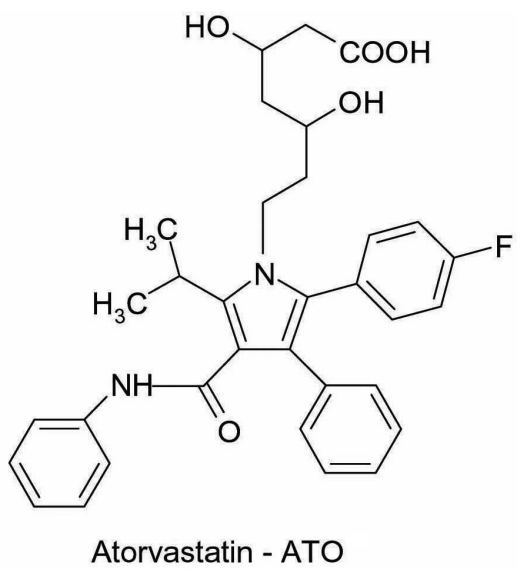

Sodium tetraborate, sodium dodecyl sulphate (SDS) were purchased from Merck (Germany) while methanol from LachNer (Czech Republic). All reagents were of analytical purity. Purified water was provided by a Milli-Q Plus water purification system (Millipore, USA).

The pharmaceutical dosage form used in this study was Liptruzet (MSD, UK) containing an EZE/ATO ratio of $10 / 40 \mathrm{mg}$.

\section{Equipment}

The measurements were performed on an Agilent $1600 \mathrm{CE}$ system equipped with a photodiode array (DAD) detector and ChemStation software for data handling. Separations were carried out in an uncoated fused-silica capillary with a total length of $48 \mathrm{~cm}(40 \mathrm{~cm}$ effective length), having an internal diameter of $50 \mu \mathrm{m}$ (Agilent, Germany). Buffer $\mathrm{pH}$ was determined using a Terminal $740 \mathrm{pH}-$ meter (Inolab, Germany).

\section{Electrophoretic procedure}

Conditioning of new capillaries was conducted by flushing with $0.1 \mathrm{M} \mathrm{NaOH}$ for 60 minutes and water for 30 minutes. Prior to all runs the capillary was preconditioned by flushing with $0.1 \mathrm{M} \mathrm{NaOH}$, water and background electrolyte (BGE) each for 2 minutes.

Stock solution containing $1 \mathrm{mg} \mathrm{mL}^{-1}$ of each analyte were prepared in methanol and diluted prior to use with the same solvent to the appropriate concentration. Both BGE and sample solutions were filtered through a $0.45 \mu \mathrm{m}$ pore size membrane filter and sonicated in an ultrasonic bath for 5 minutes prior to use.

In the preliminary analysis we applied some "standard" electrophoretic conditions for a CE analysis: $25 \mathrm{mM}$ buffer concentration, temperature $20{ }^{\circ} \mathrm{C}$, applied 
voltage $+20 \mathrm{kV}$, injection pressure $\mathrm{x}$ time 50 mbar $\mathrm{x} 3$ sec, sample concentration $25 \mu \mathrm{g} \mathrm{mL}^{-1}$. The samples were introduced in the system at the anodic end of the capillary by hydrodynamic injection. Detection was performed at 210,230 and $250 \mathrm{~nm}$, and full spectra of the analytes were also stored to facilitate peak identification.

\section{Preparation of pharmaceutical samples}

When preparing samples from commercial formulations, average weight was calculated by weighing 10 tablets, the tablets were crushed, mixed and powdered in a mortar into a homogenous powder; an amount of powder equivalent to the weight of one tablet was dissolved in 100 $\mathrm{mL}$ methanol by sonication for 5 minutes with intermittent shaking. The solution was filtered through a $0.45 \mu \mathrm{m}$ syringe filter, centrifuged at $3500 \mathrm{rpm}$ for 10 minutes and diluted with methanol to the appropriate concentration. The same procedure was applied as in the separation from standard solutions.

\section{RESULTS AND DISCUSSION}

\section{Optimization of the analytical conditions}

The $\mathrm{pH}$ value is always a critical selectivity parameter for the determination of acidic and basic compounds, as it determines the ionization degree of the analytes, their electrophoretic mobility and the magnitude of the electroosmotic flow (EOF). The effective mobility of weak anionic and cationic analytes is strongly dependent on their $\mathrm{pKa}$ values related to the $\mathrm{pH}$ of the running buffer.

Preliminary CZE measurements were attempted with different phosphate and borate buffer solutions in a $\mathrm{pH}$ range between 3 and 11; ATO can be determined over a relatively large $\mathrm{pH}$ range (5-11) being completely ionized in anionic forms in neutral and alkaline $\mathrm{pH}$ environments, EZE can be determined only in an acidic environment while over a $\mathrm{pH}$ range between $5-11$ presents no own electrophoretic mobility and will be carried by the EOF.

Consequently micellar electrokinetic capillary chromatography (MEKC) was applied for the separation of the two analytes by adding an anionic surfactant, sodium dodecyl sulfate (SDS), to the buffer electrolyte. MEKC is based on the addition to the buffer solution of a micellar "pseudostationary" phase, which interacts with the analytes according to partitioning mechanisms, just like in a chromatographic method where the "pseudostationary" phase is composed by the surfactant added to the buffer solution in a concentration above its critical micellar concentration (CMC) and EOF acts like a chromatographic "mobile phase". The separation principle of MEKC is based on the differential partition of the analytes between micelles and water, as analytes which are highly retained by the micelle will have longer migration times (Hancu et al., 2013).

The optimization of the electrophoretic separation was based on the production of acceptable peak shape, resolution and separation time. Optimization of the developed method was performed in an univariate manner, changing one factor at a time, while keeping the others constant, in terms of BGE concentration (25-100 mM), BGE pH (8-11), SDS concentration (20-50 mM), applied voltage $(15-30 \mathrm{kV})$, capillary cassette temperature $\left(15^{\circ} \mathrm{C}-25\right.$ ${ }^{\circ} \mathrm{C}$ ) and injection parameters (25-50 mbar x 1-5 seconds).

The effect of buffer $\mathrm{pH}$ was investigated in the range 8 - 11 using a $25 \mathrm{mM}$ sodium tetraborate, $25 \mathrm{mM}$ SDS buffer; the best correlation between migration times, resolution and peak shapes were obtained at $\mathrm{pH}$ 9.3.

The effect of running buffer concentration was examined by varying it between 25 and $100 \mathrm{mM}$ at a constant $\mathrm{pH}$ of 9.3. An increase in buffer concentration generated higher currents and increased migration time, consequently a concentration of $25 \mathrm{mM}$ was chosen in order to reduce analysis time.

The effect of surfactant concentration was assessed in the range of $20-50 \mathrm{mM}$, the increase of SDS concentration resulted in increased migration times, consequently the optimum SDS concentration was set to $25 \mathrm{mM}$.

The effects of organic modifiers like acetonitrile or methanol in the concentration range of $5-20 \%$, were also evaluated, but only an increase in migration times was obtained and no improvement on the electrophoretic separation was achieved.

The effect of the separation voltage in the range of $15-30 \mathrm{kV}$ was examined, high voltage reduces analysis time while low voltage enhances separation, a voltage of $+30 \mathrm{kV}$ was selected as the optimum.

The influence of capillary temperature $\left(15-25^{\circ} \mathrm{C}\right)$ was evaluated; when temperature increased migration times decreased; a temperature of $20^{\circ} \mathrm{C}$ was chosen as working temperature for the analysis.

In order to determine the optimal injection parameters, the influence of injection time (1-5 s) and injection pressure (25-50 mbar) were studied. An injection pressure of 50 mbar and an injection time of 1 second proved to be appropriate to attain low detection limit without affecting the peak shape, migration time and resolution.

The best results for the simultaneous determination of ATO and EZE were obtained when using $25 \mathrm{mM}$ borate 


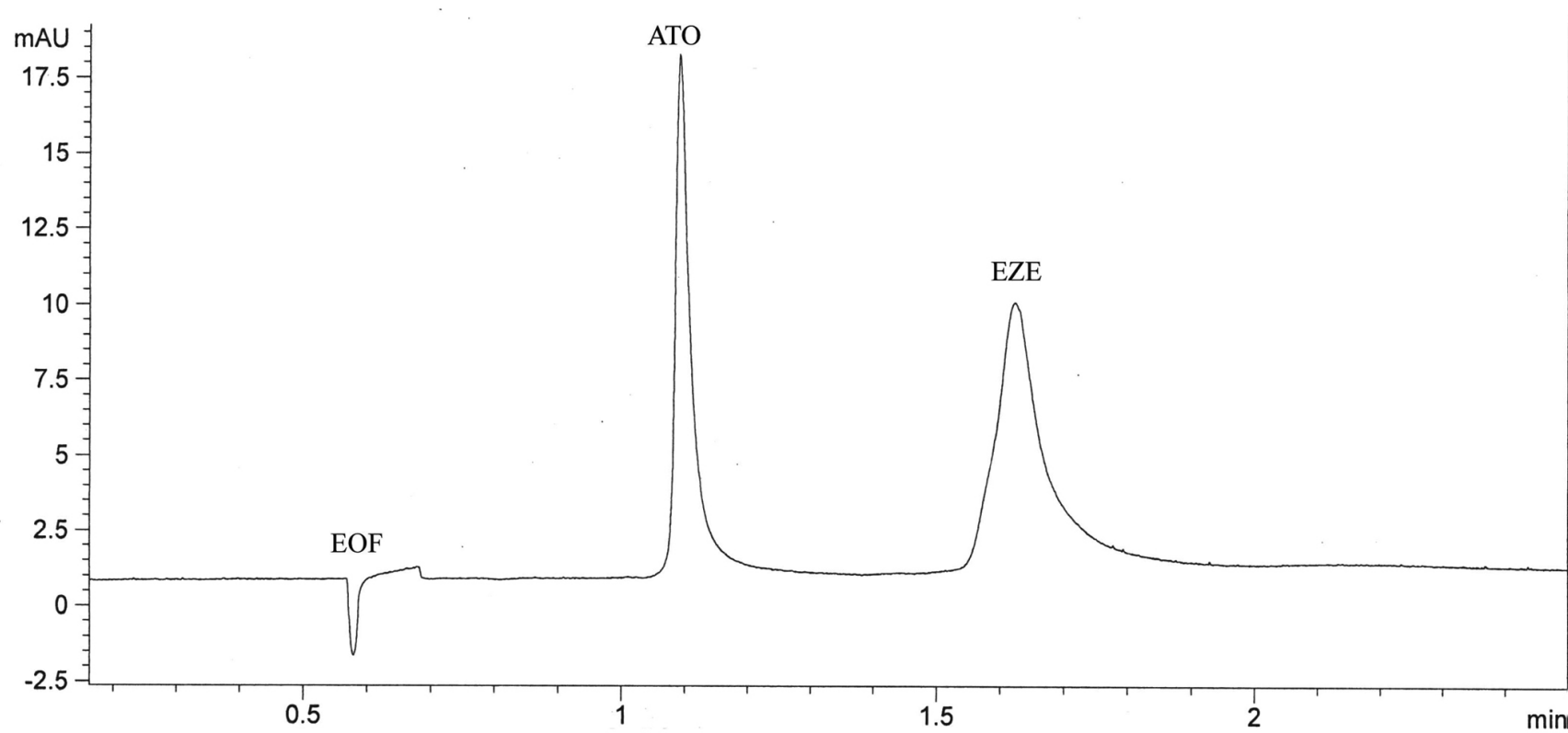

FIGURE 2 - Capillary electrophoretic separation of atorvastatin (ATO) and ezetimibe (EZE), (experimental conditions: 25 mM borate buffer electrolyte at $\mathrm{pH} 9.3$ containing $25 \mathrm{mM} \mathrm{SDS},+30 \mathrm{kV}$ applied voltage, $20^{\circ} \mathrm{C}$ system temperature, $50 \mathrm{mbar} / \mathrm{s}$ injection parameters, UV detection $230 \mathrm{~nm}$ ).

buffer containing $25 \mathrm{mM}$ SDS at $\mathrm{pH} 9.3,+30 \mathrm{kV}$ applied voltage, $20^{\circ} \mathrm{C}$ system temperature, injection pressure 50 mbar, injection time 1 second, UV detection at $230 \mathrm{~nm}$. The two analytes migrated in less than 2 minutes, the order of migration was ATO followed by EZE; the resolution of the separation was 7.02 with a selectivity factor of 1.49 (Figure 2).

\section{Analytical performance}

Linearity solutions were prepared from stock solution at six concentration levels and three replicates per concentration. The linear regression analysis of ATO and EZE were constructed by plotting the peak area of the analytes $(\mathrm{y})$ versus analytes' concentration in $(\mathrm{x})$ axis. The calibration curves were linear in the studied range (5-100 $\left.\mu \mathrm{g} \mathrm{mL}^{-1}\right)$ with correlation coefficients above 0.99 . The regression equation and correlation coefficients are presented in Table I.

The approach based on the standard deviation of the response and the slope of the calibration plots was used to determine detection (LOD) and quantification (LOQ) limits. LOD and LOQ values were estimated as [(standard deviation of repeatability)/(slope of the regression equation)] by multiplying with 3.3 and 10 respectively. The values obtained are given in Table I.

The intra-and inter-day variability or precision are summarized in Table II and were assessed by using standard solutions prepared to produce solutions of three different concentrations of each drug. Repeatability or intra-day precision was investigated by injecting six replicate at of each of the samples of three different concentrations. Inter-day precision were assessed by injecting the same three samples over three consecutive days.

To demonstrate the robustness of the method, minor changes in the experimental conditions were performed; as $\mathrm{pH}$ of the buffer was varied in the range $\pm 0.5 \mathrm{pH}$ unit, separation temperature in the range $\pm 2{ }^{\circ} \mathrm{C}$ while applied voltage in the range $\pm 2 \mathrm{kV}$. None of the modifications caused significant changes in the resolution. The RSD for migration times and peak areas was under $3 \%$.

TABLE I - Analytical parameters for the simultaneous determination of ATO and EZE $(n=6)$

\begin{tabular}{|c|c|c|c|c|c|}
\hline Analyte & $\begin{array}{l}\text { Concentration } \\
\text { range }\left(\mu g \mathrm{~mL}^{-1}\right)\end{array}$ & Regression equation & $\begin{array}{c}\text { Correlation } \\
\text { coefficient }\end{array}$ & $\begin{array}{c}\text { LOD } \\
\left(\mu \mathrm{g} \mathrm{mL}^{-1}\right)\end{array}$ & $\begin{array}{c}\text { LOQ } \\
\left(\mu \mathrm{g} \mathrm{mL}^{-1}\right)\end{array}$ \\
\hline$\overline{\mathrm{ATO}}$ & $5-100$ & $y=0.8279 x+8.3137$ & 0.9965 & 0.27 & 0.89 \\
\hline EZE & $5-100$ & $y=0.9114 x+8.0645$ & 0.9981 & 1.29 & 4.31 \\
\hline
\end{tabular}


TABLE II - Intra and inter-day precision for the simultaneous determination of ATO and EZE

\begin{tabular}{lllll}
\hline \multirow{2}{*}{$\begin{array}{l}\text { Analyte concentration } \\
\left.\boldsymbol{\mu} \mathbf{g} \mathbf{~ m L}^{-1}\right)\end{array}$} & \multicolumn{3}{c}{ RSD (\%) } \\
\cline { 2 - 5 } & ATO & EZE & ATO & Peak area \\
\cline { 2 - 5 } & & & & \\
\hline Intra-day precision $(\mathbf{n}=\mathbf{6})$ & 0.95 & 1.05 & 1.27 & 2.17 \\
\hline 10 & 0.94 & 1.06 & 1.22 & 2.18 \\
20 & 0.95 & 1.06 & 1.14 & 2.02 \\
\hline 30 & & & & \\
\hline Inter-day precision $(\mathbf{n}=\mathbf{1 8})$ & 1.04 & 1.51 & 2.55 & 2.75 \\
\hline 10 & 1.03 & 1.48 & 2.42 & 2.68 \\
20 & 1.05 & 1.53 & 2.47 & 2.73 \\
\hline 30 & & & & \\
\hline
\end{tabular}

TABLE III - Assay results of ATO and EZE simultaneous determination in pharmaceutical formulation

\begin{tabular}{lcccccc}
\hline $\begin{array}{l}\text { Pharmaceutical } \\
\text { preparation }\end{array}$ & \multicolumn{2}{c}{ Declared amount (mg) } & \multicolumn{2}{c}{ Found amount (mg) } & \multicolumn{2}{c}{ RSD (\%) } \\
\cline { 2 - 7 } & ATO & EZE & ATO & EZE & ATO & EZE \\
\hline Liptruzet 10/40 & 40 & 10 & 40.8 & 9.9 & 0.85 & 1.62 \\
\hline
\end{tabular}

The solution stability of ATO and EZE was carried out by leaving the test solution in tightly capped volumetric flask at room temperature for 24 hours. The sample solution was assayed against freshly prepared standard solutions, the RSD of the assay of ATO and EZE were within 5\% and it indicates that both standard and test preparation were stable for 24 hours on benchtop at room temperature.

The electropherograms obtained from tablets were similar to those obtained from standard solutions. There were no interfering peaks of excipients with the analytes. The $\%$ recovery was found to be in the range of $98-102 \%$ indicating high degrees of accuracy of the proposed method (Table III).

\section{CONCLUSION}

AMEKC method for the simultaneous determination of ATO and EZE was successfully developed. A conventional method optimization based on changing one variable at a time, while keeping the other variables constant was applied in order to establish the optimal analytical conditions. Under the optimized conditions, baseline separation of the two analytes was obtained in approximately 2 minutes. In comparation with the results published by AlShehri (2012) much shorter migration times and comparable resolution were obtained by applying a MEKC technique instead of CZE (2 minutes versus 15 minutes).
Good analytical performance with regards to linearity, precision, reproductibility and robustness was achieved. Furthermore, the proposed method was successfully applied for the determination of the analytes in their co-formulated tablets.

\section{ACKNOWLEDGMENTS}

This work was supported by the Department of Medical and Pharmaceutical Sciences of the Transylvanian Museum Society, Romania and the Faculty of Pharmacy of Semmelweis University, Hungary (No. 63/2015/P.2/ EMEOGYSZ).

\section{REFERENCES}

ALSHEHRI, M.M. A validated capillary electrophoresis method for simultaneous determination of ezetimibe and atorvastatin in pharmaceutical formulations. Saudi Pharm. J., v.20, n.2, p.143-148, 2012.

ARA, R.; TUMUR, I.; PANDOR, A.; DUENAS, A.; WILLAMS, R.; WILKINSON, A.; PAISLEY, S.; CHILCOTT, J. Ezetimibe for the treatment of hypercholesterolaemia: a systematic review and economic evaluation. Health Technol. Assess., v.12, p.1-212, 2008. 
BAGHDADY, Y.Z.; AL-GHOBASHY, M.A.;ABDEL-ALEEM, AAE; WESHAHY, SA. Spectrophotometric and TLCdensitometric methods for the simultaneous determination of Ezetimibe and Atorvastatin calcium. J. Adv. Res., v.4, p.51-59, 2013.

BALLANTYNE, C.M.; HOURI, J; NOTARBARTOLO, A.; MELANI, L.; LIPKA, L.J.; SURESH, R.; SUN, S.; LEBEAUT, A.P.; SAGER, P.B.; VELTRI, E.P. Effect of ezetimibe coadministered with atorvastatin in 628 patients with primary hypercholesterolemia: a prospective, randomized, double-blind trial. Circulation, v.107, p.2409$2415,2003$.

DALMORA, S.L.; OLIVEIRA, P.R.; BARTH, T.; TODESCHINI, V. Development and validation of a stability-indicating micellar electrokinetic chromatography method for the determination of ezetimibe in pharmaceutical formulations. Anal. Sci., v.24, p.499-503, 2008.

EL-BAGARY, R.I.; ELKADY, E.F.; EL-SHERIF, Z.A.; KADRY, A.M. LC-MS-MS simultaneous determination of atorvastatin and ezetimibe in human plasma, J. Chromatogr. Sci., v.52, p.773-780, 2014.

GAGNÉ, C.; GAUDET, D.; BRUCKERT, E. Efficacy and safety of ezetimibe coadministered with atorvastatin or simvastatin in patients with homozygous familial hypercholesterolemia. Circulation, v.105, p.2469-2475, 2002.
HANCU, G.; SIMON, B.; RUSU, A.; MIRCIA, E.; GYÉRESI, Á. Principles of micellar electrokinetic capillary chromatography applied in pharmaceutical analysis. $A d v$. Pharm Bull.,v.3, p.1-8, 2013.

MALHOTRA, H.S.; GOA, K.L. Atorvastatin: an updated review of its pharmacological properties and use in dyslipidaemia. Drugs, v.61, p.1835-1881, 2001.

MORZUNOVA, T.G. Capillary electrophoresis in pharmaceutical analysis. Pharm. Chem. J., v.40, p.158$170,2006$.

PATEL, A.; MACWANA, C.; PARMAR, V.; PATEL, S. Simultaneous determination of atorvastatin calcium, ezetimibe, and fenofibrate in a tablet formulation by HPLC. J. AOAC Int., v.95, p.419-423, 2012.

SECHACHALAM, U; KOTHAPALLY, CB. HPLC analysis for simultaneous determination of atorvastatin and ezetimibe in pharmaceutical formulations. J. Liq. Chromatogr. Rel. Tech., v.31, p.714-721, 2008.

YARDIMCI, C; ÖZALTIN, N. Simultaneous determination of ezetimibe and simvastatin in pharmaceutical preparations by MEKC. J. Chromatogr Sci., v.48, p.95-99, 2010.

Received for publication on $28^{\text {th }}$ June 2016 Accepted for publication on $25^{\text {th }}$ October 2016 